\title{
SOCIAL COMMUNICATION OF CHILDREN YOUNGER SCHOOL AGE IN THE DIGITAL ERA
}

\section{Bozena Supsakova*}

\author{
*Prof. Dr., Comenius University, Faculty of Education, Bratislava, Slovakia, supsakova@gmail.com
}

\begin{abstract}
The Internet, a new phenomenon of the global information infrastructure and access to information, was born in the seventies of the last century and began to affect significantly the way we communicate, collect and share information. Nowadays, it penetrated to new dimensions of its development, as developing multimedia technologies and content (Web 2.0), as well as new phenomenal contacts: mobile communications (mobile phones, smart phones, tablets) and social networks (Facebook, Twitter and a lot of others). The Internet is used nowadays worldwide by one third of people, we register incredible five billion subscribers to mobile services; in economically developed countries one user has more than one prepaid mobile service. This modern paradigm obviously affected and influenced also the younger generation. It is clear that the time that has come requires to learn new literacy -media literacy, but also to gain or acquire new social skills, especially how to orient, and most recently, to self-realize in the multimedia on-line space. This is a series of new communications competences and skills that include the ability to search, select, analyse, evaluate, create, and thus to pass information in variety of formats - by word, image, sound. Recently, it includes also with the integration of all these elements - it means the multimedia integration. Our study explore the extent to which children of nowadays communicate through the electronic media, and how much time they spend watching the individual kinds of media.
\end{abstract}

Keywords: social networks, new communication competences, new literacy of children younger school age, preferred ways and forms of communication, digital literacy, media literacy, media education curriculum.

\section{INTRODUCTION}

Globalization and the use of online internet technologies (particularly through development social networks, forums and blogs, the rising mobility of users and the rapid growth of digital product), have changed the ways and forms of communication, mainly at the young generation. It is due to their new, attractive, actionlike and in many cases also interactive form of influence. The aim of our study is to find out the role of the new literacy children younger school age in the process of acquiring information, education. Our priority is also to explore the extent to which children of nowadays communicate through the electronic media, and 
how much time they spend watching the individual kinds of media. Simultaneously, we aim at exploring the types of medial context the youth is interested in, how they perceive these contexts, and if they are able to select the kind of information from the medial production that develop their individual and group needs. We tend to clarify if and how the medial technologies are used for the creative expression and communication through own ideas, information and opinions. Our task is also to find out to what degree children are able to distinguish the medial contexts and notionally almost worthless information from the information of practical importance to their lives. We look for the answer to the question on which sources of information they consider inevitable for their lives, what they predominantly look for in their preferred media, and what level of confidence they show towards the media. Within the topic we are going to deal with the question on the preferred way of communication which the young people develop with close friends. We assume that the young fully use all available sources of information intended for education, amusement with a distinct prevalence of the field of study. According to our opinion, intensity of using the individual kinds of media is gradually shifted from the passive forms of TV watching, listening to the radio, reading print media towards the interactive forms of communication in the internet environment (web2.0 - social networks, portals and blogs, chatting). We also assume that young people show greater confidence in the new media (internet). The research aimed at the study of nowadays communication tools and behaviour in the online environment is implemented on the sample of 1452 children younger school age (7-11) in Slovakia.

\section{SOCIAL NETWORKS - NEW PHENOMEN}

The Internet, a new phenomenon of the global information infrastructure and access to information, was born in the seventies of the last century and began to affect significantly the way we communicate, collect and share information. Nowadays, it penetrated to new dimensions of its development, as developing multimedia technologies and content (Web 2.0), as well as new phenomenal contacts: mobile communications (mobile phones, smart phones, tablets) and social networks (Facebook, Twitter and a lot of others). The Internet is used nowadays worldwide by one third of people, we register incredible five billion subscribers to mobile services; in economically developed countries one user has more than one prepaid mobile service (Potter, 2012). This modern paradigm obviously affected and influenced also the younger generation.

\subsection{New literacy and new skills}

It is clear that the time that has come requires to learn new literacy - media literacy, but also to gain or acquire new social skills, especially how to orient, and most recently, to self-realize in the multimedia on-line space. This is a series of new communications competences and skills that include the ability to search, select, analyse, evaluate, create, and thus to pass information in variety of formats - by word, image, sound. Recently, it includes also with the integration of all these elements - it means the multimedia integration.

Media literacy is defined by most policymakers and academics as the ability to "access, analyse, and evaluate media" in multiple forms and "communicate competently" within these forms (Livingstone, Bober, Helsper, 2005, O’Neill \& Hagen, 2009). Traditionally, education, training and lifelong learning policies have been perceived as critical to developing media literacy. Therefore, any future interventions in this area must take into account that media messages are constructed, have a purpose, may be affected by potential biases, and are subject to regulatory issues that potentially affect access and use (Martens, 2010, Ofcom, 2008).

At the theoretical level, media literacy can therefore be characterized as an ability to seek, receive, analyse, evaluate and communicate (multi) media content. "Media literacy is a summary of competences that allow us to interpret the media content and processes of the media world to create our own media, to recognize and deal with the social and political impact of media in everyday life" (Hoechsmann \& Poyntz 2012). While the media content (news, music, web sites) are produced by broadcasters, film-makers, web designers, and are mediated by media technologies (television, film, digital technologies such as smart phones, mp3 players, tablets or digital cameras). An interesting view on media literacy was expressed by a prominent expert and author of Media Literacy, W. J. Potter, who says that "to become more media literate means a boundary between your real world and the world, produced by media. Being media literate also means getting the information and experience you want, without having to get out of the media what you do not want. Then you will be able to create your life as you want, and do not allow the media to create it as they want - on your behalf" (Potter, 2012). The author clearly comes up to the contemporary world of media, which continues its unprecedented development and is beyond the power of human senses to cover all new information created every day. Bearing in mind that every day in the world 1500 new titles of books are published, radio stations broadcast 65.5 million hours of the original program per year, televisions 48 million hours. At present, 35 million websites are available, Internet users send 300 billion emails per day, on YouTube 50 thousand hours of new videos are added daily, and in the short messaging social network known as Twitter, 70 million twitties a day are sent. People spend with new media more and more time, on 
average it is 8 hours a day - all studies over the past three decades confirm that. Children (and young people) in Slovakia are not an exception.

\subsection{The European approach to media literacy}

The public space thus offers countless sources of information, which is increasingly difficult to orient in and to verify its validity and relevance. The media reality is not always an "actual" reality; the boundaries between "true" and "false" are vague and often fictitious. This virtual world is naturally attractive, especially for children (and youth) and the part of the population is among the first to be able to acquire new skills quickly and thus to obtain gradually a new - media - literacy.

Young people crave much more frequently than adults to control new technologies and know to manage them very easily while their cognitive skills and the ability to make decisions based on values are not yet fully developed. Globalization and convergence of media, along with a wide range of options they offer arouse also new concerns: flood of information; uniformity undoubtedly caused by the dominance of one language and one culture in the new media, the increasing commercialization. There is also a serious risk of a new form of social exclusion for those who cannot communicate through the media and/or are unable to assess their content critically.

The European approach to media literacy covering all media and media literacy levels includes (Recommendation of Commission No. 6464/2009, 2009):

1. Feeling of comfort when using all existing media from newspapers to virtual communities;

2. Active use of media through interactive television, use of Internet search engines or participation in virtual communities and better exploiting of the potential of media for entertainment, cultural and inter-cultural dialogues, learning and everyday applications (e.g. libraries, webcast and podcast services);

3. Critical approach to media in terms of quality and accuracy of their content (e.g. the ability to evaluate information, (prudent) perception of advertising in various media, smart use of search engines);

4. Creative exploiting of media, since the evolution of media technologies and the growing importance of the Internet as a distribution channel allow the growing number of Europeans to create and disseminate images, information and content;

5. Understanding of economic relations in the media industry and the difference between pluralism and media ownership, awareness of copyright issues, which is needed for so-called culture of legality, especially for the younger generation in its double position as consumers and content producers.

\subsection{The research in Slovakia}

Our research adds that in Slovakia children 7-11 years old spend about 5 hours watching a screen. Daily they read only for 1 hour and 20 minutes, while $87 \%$ of them focus mostly on the text and $13 \%$ on images (illustration), 11 to 14 year old children 7 hours daily watch TV and read daily 1 hour, while $78 \%$ of them focus on the text and 22\% on images (illustration) (Supsakova, 2010, 2014). In frame of the another project in Slovakia, an on-line survey panel of active Internet users, confirmed that the most frequently used activities with mobile phones carried out by children include making calls, sending SMS or MMS messages, taking photographs, listening to music or radio and playing games. The survey results indicate that children of parents, who themselves actively use the Internet, spend too much time on-line and the most frequently is the Internet used by the eldest children, i.e. of $16-19$ years of age, daily $(76 \%)$ or several times a week $(20 \%)$. The most common activities of youth (16-19 years) on the Internet are searching for information $(89 \%)$, chatting (88\%), emails (79\%), and downloading of music, pictures and movies (76\%). Youngest children (6-9 years) spend most of the time playing on-line games, and most of all seeking entertainment and information, contacts of their family and friends, as well as contacts for new friends. Provision of data through the Internet is risky, particularly in the age group from 10 to 19 years. The most common information provided through the Internet includes email address, photo, phone number and home address (Project Zodpovedne.sk, 2008).

Regarding the threats and risks on the Internet "more than a quarter of interviewed children are aware of being in a risky situation sometimes. It is often stated that the younger children having met more risks. It could be related to a raising awareness of Internet risks as well as that a lot of activities on the Internet is done by still younger children when they are not able to handle difficult situations (this age shift has been a long-term trend). Children aged 8-11 have got less technical skills and experiences with social situations. They have not got developed their abstract and critical thinking sufficiently yet and are not able to consider consequences of their actions properly, what are significant disadvantages in decision making in ambiguous situations" (Tomkova, 2012). 


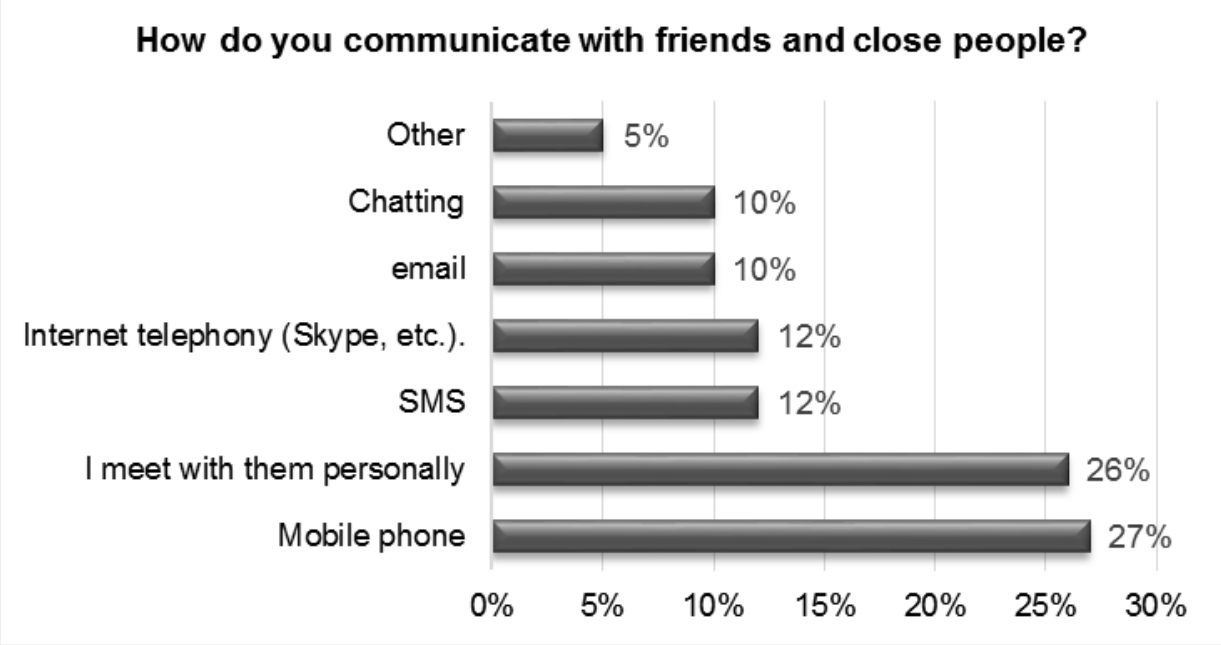

Fig. 1. How children communicate with friends and close people. N: 1452

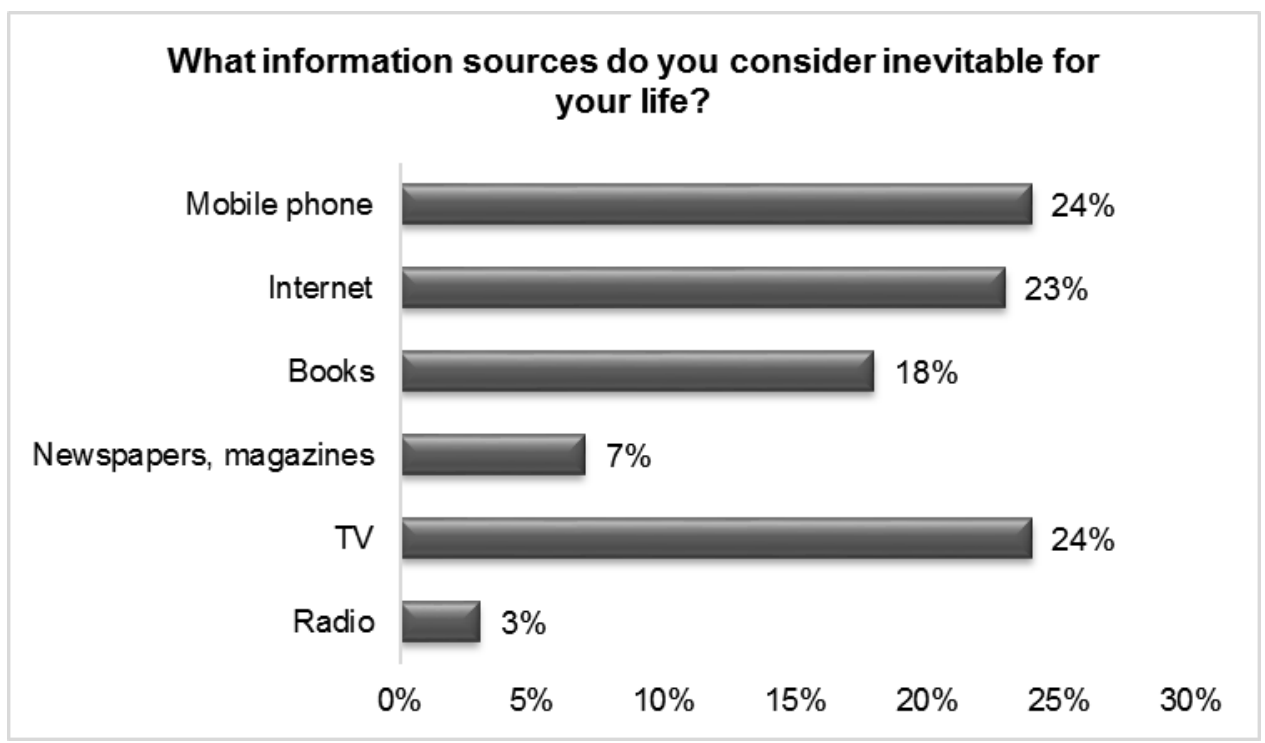

Fig. 2. Preferences of children: information sources inevitable for their life. N: 1452

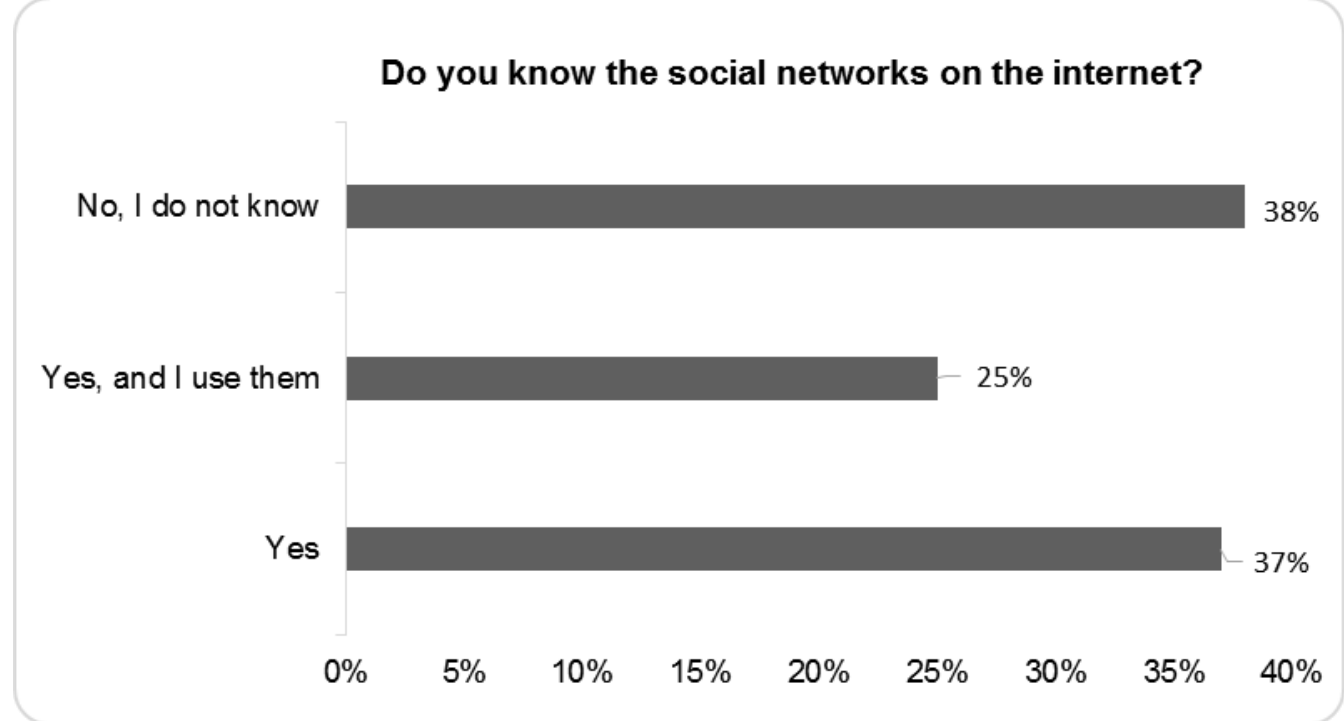

Fig. 3. Knowledge of social networks among children. N: 1452 
Research of D. F. Roberts and U.G. Foehr shows that at average a child and young person (8-18 years) spend in the new media ecosystem up to 7 hours 50 minutes a day, and the new trend is to use multiple functions and resources at the same time (so called multitasking - performance of several activities at once), when e.g. a young man is listening to music on the Internet, at the same time chatting with friends and in another window on the screen watching video (Roberts \& Foehr, 2008). It is not surprising that this generation of children and teenagers acquires the name „M generation“, i.e. a generation strongly linked with media (Potter, 2012). We can definitely say that if in the past media literacy was linked mostly with written words, now it is not valid, as new types of literacy enter our lives -visual literacy, computer literacy, context (content) literacy.

\section{INOVATION IN THE CURRICULUM}

Media education creates a space for young people to express free and the right to information. It is beneficial not only for their personal development, but it enhances participation and interactivity in society. Thus it prepares them for democratic citizenship and political consciousness. As pointed out also in studies of Buckingham, education for media literacy is „a potentially very significant place to define future civic attitudes of individuals, especially in the ability to combine basic procedures in the field of gathering and analysing of media messages with civic participation and social action“ (Buckingham, 2000). As he further notes, „the media education curriculum must socialize young people, to acquire experiences from social changes"(Buckingham, 2000). We can also agree with the Thomans and Jolly who say that education can "begin in the classroom, but culminates in a meaningful, creative participation of individuals in a broader cultural and social environment, and leads to personal and political transformation from a passive observer of events to an actionable citizen who can take interested citizen attitudes" (Thomas \& Jolly, 2004).

Media education is here to help children to cultivate their curiosity to learn how to assess various issues and situations in contexts and in a complex, to accept diverse perspectives and think optimistically to the future. Reflected into the educational practice, media education at the primary level of education should include all personal levels of children/students as well as cognitive (basic orientation in the media environment, recognizing of differences and diversity, decoding of reality represented by media, understanding the positive and negative impacts of the media, etc.), psychomotoric (active communication in the media environment, creation of their own media content, ability to collaborate and communicate with the media environment), and attitudinal (the ability to take their own attitude to media products, the ability of critical analysis, responsibility for content creation, etc.). Also in this case it would be valid that the practice is the criterion of truth. The media environment should become a textbook as well as a kind of laboratory of media education in schools.

\section{CONCLUSION}

Although media education is part of the curriculum in many European countries, the Member States, its practical application is still problematic, even in relation with traditional media. Qualified teachers and educational materials are an essential condition of media education, and therefore the constant attention should be paid to teacher training in primary schools, as well as at other levels of education. Uncertainties remain in question, which place would media education have in the curriculum, what goals and tasks should be fulfilled. Also uncertainties remain in education methodology and assessment of results. "Most schools are still not adapted to the educational model, in which students and teachers are in a position of learning"( Recommendation of Commission No. 1466/2000, 2000). This statement concerning deficiencies in media education throughout Europe unfortunately persists till today. Involved professionals, experts in media education identified misunderstanding and lack of status of the subject and its content in the educational system, incompetent teaching, inadequate teacher education, lack of basic educational facilities, lack of funds, etc.

We share the same opinion with recommendations of experts in media education (Testing and Refining Criteria to Assess Media Literacy Levels in Europe, 2011) that are necessary several steps to improve the situation:

- Initiatives and founding sources should be provided for national governments of Member States to exchange experiences with countries.

- Measurements tools should be introduced as integral parts of media education. It would particularly allow long term observations of trends, and would provide systematic measurements of skill levels and of cognitive critical thinking elements:

- Traditional media access/exposure

- Exposure to Internet and social networks

- Use skills (computer and Internet skills, and more sophisticated skills measurement for all media in educational systems) 
- Protection skills: ability to change their privacy settings or to block other users online, from EU kids online content creation skills

- Content creation: making videos/taking photos on digital video, digital camera and mobile phones, SMS messages, post messages on Internet

- The manifestation of communicative abilities into media content is most characteristic among young populations. To extend the population that is active in these fields, secondary and tertiary education as well as lifelong learning initiatives targeting mature and elderly populations should promote the uptake of these elements of media literacy as key competences and skills and should promote the development of didactical tools, and extend teachers training programs of media teachers.

- The development of practical, "easy-to-follow" educational tools or guidance sheets for media teachers.

This finding can be even more applied to the Slovak reality, where media education is only in the beginning. It is true that the legislative framework for media education and its anchoring in the system of formal and informal education in Slovakia we already have. Talking about basic education, in addition to the results of the experimental verification there are no relevant outcomes, even there is no known extent (and whether the education exists at all), and in particular, in what quality the education is performed, how teachers teach the subject, how many professionally trained teachers we actually have. It's a challenge for our applied research to evaluate the quality of school education programs just in this field and uncover possible deficiencies (Grant Ministry of Education, Science, Research and Sport SR, KEGA 023UK-4/2012, KEGA 007UK-4/2015). Now we cannot speak about a coordinated education system, where the activities of the state are linked with the activities of non-governmental and civil sectors. Minus is the lack of the Media Education Centre at the Ministry of Culture to be the coordinator of activities in the field of media education; it was to develop the concept of media education in non-formal education, plans and projects for the development of media education system. The commitment to establish it as part of the existing institutions at the Ministry of Culture failed because of austerity.

Today we have no other option, just keep doing what we started. Media education at primary and secondary levels of basic schools definitely deserves adequate attention because as a cross-cutting theme can enrich each pupil, but also teaching such subjects as mother language, history, geography, art. It is actually a good investment.

\section{REFERENCE LIST}

Buckingham, D. (2000). The making of citizens: Young people, news and politics (pp. 221-223). London: Routledge.

Genius loci - the development program of primary school children cultural literacywith the support of new medias. Project Ministry of Education, Science, Research and Sport SR KEGA 007UK-4/2015, Božena Šupšáková, chief project.

Hoechsmann, M., \& Poyntz, S. (2012). Media literacies: A critical introduction. Oxford: Blackwell Publishing Ltd.

Interdisciplinary based educational model development and their implementation to state curriculum. Project Ministry of Education, Science, Research and Sport SR KEGA 023UK-4/2012, Božena Šupšáková, chief project.

Livingstone, S., Bober, M., \& Helsper, E. (2005). Internet literacy among children and young people: Findings from the UK children go online project. London: LSE Research Online. Retrieved from http://eprints.Ise.ac.uk/397/1/UKCGOonline Literacy.pdf.

Martens, H. (2010). Evaluating media literacy education: Concepts, theories and future directions. Journal of Media Literacy Education, 2, 1-22.

Ofcom. Office of Communications. Social Networking A quantitative and qualitative research report into attitudes, behaviours and use. Research Document. Publication date: 2 April 2008. Retrieved from http://stakeholders.ofcom.org.uk/binaries/research/media-literacy/report1.pdf.

O'Neill, B., \& Hagen, I. (2009). Media literacy. Kids online: Opportunities and risks for children. Sonia Livingstone and L. Haddon (eds.). Bristol: Policy Press: 229-239.

Potter, W. J. (2012). Media literacy. London: SAGE Publishing.

Project Zodpovedne.sk. (2008). Child safety in the use of Internet and mobile phone. Retrieved from http://www.zodpovedne.sk

Recommendation of Commission No. 1466/2000. (2000). Media education. Council of Europe, The 
Parliamentary Assembly. Retrieved from http://www.culture.gov.sk/extdoc/2636/.

Recommendation of Commission No. 6464/2009. (2009). Commission recommendation on media literacy in the digital environment for a more competitive audiovisual and content industry and an inclusive knowledge society, Brussels. Retrieved, August 20, 2009, from http://ec.europa.eu/culture/media/literacy/docs/recom/c_2009_6464_sk.pdf.

Roberts, D. F., \& Foehr, U. G. (2008). Trends in media use. The Future of Children, 18(1), 11-37.

Šupšáková, B. (2010). Reflection of the media in expressing the image of children and youth. In J. Mašek, Z. Sloboda, \& V. Zikmund (Eds.), Media education in theory and practice, Pilsen (pp. 138-147). Pilsen: Faculty of Education, University of West Bohemia.

Šupšáková, B. et al. (2014). The Media Literacy of Young Children and Young People. Bratislava: Iris. Retrieved from electronic publication http://www.arteducation.sk/publikacie-studieclanky/detail/medialna-gramotnost-deti-na-slovensku/vlastna-monografia/.

Šupšáková, B. (2013). New Media and Social Networks as a New Phenomenon of Global Access to Information and Education. US-China Education Review A, August 2013, 3(8), 623-635.

Testing and Refining Criteria to Assess Media Literacy Levels in Europe. (2011). European Association for Viewers' Interests \& Danish Technological Institute, Final Report, p. 14.

Thomas, E., \& Jolly, St. (2004). Media literacy: A national priority for a changing world. American Behavioral Scientis, 48(1), 18-29.

Tomkova, J. (2012). Mediation of safer internet use (p. 3). The Survey Final Report, Research Institute for Child Psychology and Pathopsychology, Bratislava. 